\title{
Wake-up stroke: Clinical characteristics, sedentary lifestyle, and daytime sleepiness
}

\author{
Deborath lucia de Oliveira Diniz ${ }^{1}$, Pedro Rodrigues Barreto ${ }^{2}$, Pedro Felipe Carvalhedo de Bruin ${ }^{3}$, \\ Veralice Meireles Sales de Bruin ${ }^{4 *}$ \\ ${ }^{1} \mathrm{MD}, \mathrm{MSc}$, Universidade Federal do Ceará (UFC), Fortaleza, CE, Brazil \\ 2Physiotherapist, UFC, Fortaleza, CE, Brazil \\ ${ }^{3} \mathrm{MD}$, PhD, Professor of Pneumology, UFC, Fortaleza, CE, Brazil \\ ${ }^{4} \mathrm{MD}, \mathrm{MSc}, \mathrm{PhD}$, Neurologist, Professor of Neurology, UFC, Fortaleza, CE, Brazil
}

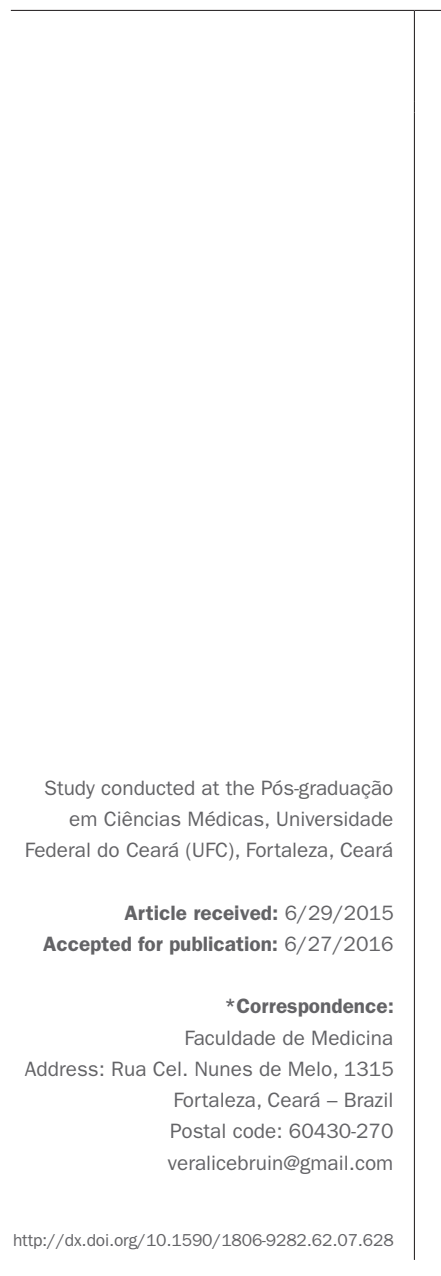

\section{SUMMARY}

Objective: Wake-up stroke (WUS) is defined when the exact time of the beginning of the symptoms cannot be determined, for the deficits are perceived upon awakening. Sleep alterations are important risk factors for stroke and cardiovascular diseases. This study evaluates the characteristics of patients with and without WUS, the presence of daytime sleepiness, and associated risk factors.

Method: Patients with ischemic stroke were investigated about the presence of WUS. Clinical and demographic characteristics were evaluated. Stroke severity was studied by the National Institutes of Health Stroke Scale (NIHSS) and the Modified Rankin Scale (MRS), and daytime sleepiness severity was studied by the Epworth Sleepiness Scale (ESS).

Results: Seventy patients ( $57.1 \%$ men) aged from 32 to 80 years $(58.5 \pm 13.3)$ were studied. WUS was observed in $24.3 \%$. Arterial hypertension (67.1\%), type 2 diabetes (27.1\%), and hyperlipidemia (22.8\%) were frequent. Type 2 diabetes and sedentary lifestyle were more common in patients with WUS $(p<0.05)$. Overall, mild, moderate or very few symptoms of stroke (NIHSS $<5$ ) were predominant (62.3\%). Among all cases, $20 \%$ had excessive daytime sleepiness (ESS $>10$ ). No differences were found between patients with and without WUS as regards stroke severity or excessive daytime sleepiness. Patients with excessive daytime sleepiness were younger and had more sedentary lifestyle $(\mathrm{p}<0.05)$. Individuals with previous history of heavy drinking had more daytime sleepiness $(\mathrm{p}=0.03)$.

Conclusion: Wake-up stroke occurs in approximately $25 \%$ of stroke cases. In this study, patients with WUS had more diabetes and sedentary lifestyle. Daytime sleepiness is frequent and is associated with sedentary lifestyle and heavy drinking.

Keywords: ischemic stroke, sedentary lifestyle, sleep, diabetes, heavy drinking.

\section{INTRODUCTION}

Among patients affected by stroke, 20 to $25 \%$ cannot precise the exact time of symptoms onset, for the deficits are perceived upon awakening. ${ }^{1-3}$ These types of stroke are denominated wake-up stroke (WUS). In such cases, the therapeutic time window which is one of the criteria for thrombolytic therapy is not available. ${ }^{4-6}$

Controversies about clinical differences, risk factors, and prognosis between WUS and "stroke while awake" remain. The majority of studies register similarities be- tween clinical characteristics and risk factors; however, there are divergences mainly regarding the evolution and clinical presentation. ${ }^{7}$

A previous study involving 17,398 patients (International Stroke Trial) observed the clinical profile and evolution of WUS and found no significant differences regarding age, gender, and average blood pressure. It has been shown that patients with WUS present less atrial fibrillation, less total anterior circulation syndrome, less compromise of consciousness, and more lacunar syndrome. It was hypoth- 
esized that WUS would be associated with a lower probability of development of functional dependence probably due to a milder clinical profile (predominance of lacunar syndrome). It has been said that despite their more benign presentations, the outcome of WUS is similar to other ischemic strokes. ${ }^{8}$ Adding to the controversy, hypertension, smoking, and worse clinical severity have been associated with stroke during sleep; however, fatality was not different between groups with WUS and stroke while awake. ${ }^{9}$

A retrospective study involving 2,289 patients, in which the Modified Rankin Scale (MRS) and the National Institutes of Health Stroke Scale (NIHSS) were used, showed that WUS was associated with worse clinical outcome. ${ }^{7}$ In opposition to these findings, another retrospective study with 1,854 patients showed a similar clinical outcome in WUS. ${ }^{10}$

It has been recognized that short sleep duration and daytime sleepiness are important risk factors for the manifestations of arterial hypertension, diabetes, and obesity. ${ }^{11}$ Recent studies show that a reduction of sleep duration increases the mortality for any cause. ${ }^{12}$ It is also shown that daytime sleepiness is an independent risk factor for the occurrence of stroke and other cardiovascular events. ${ }^{13}$ Together, these findings indicate that sleep alterations are important risk factors for stroke. Moreover, sedentary lifestyle and excessive alcohol drinking have been recognized as potentially harmful to health. ${ }^{14}$ Given that clinical characteristics of WUS are still conflicting, additional studies on this subject can provide insight into the pathological mechanisms of this condition and suggest new therapeutic approaches.

The objectives of this study were to evaluate clinical characteristics of patients with WUS as compared to general ischemic stroke, and to further examine the relationship with excessive daytime sleepiness, sedentary lifestyle, and heavy drinking.

\section{Method}

\section{Study design}

A cross-sectional study was performed on ischemic stroke patients admitted to a single academic stroke center from 2013 to 2014. Initially, 114 patients that filled the eligibility criteria and agreed to participate in the study were recruited. Forty-four patients were excluded due to clinical deterioration, waiver, exceeding the time limit inclusion, transfer to support hospitals and/or hospital discharge (Figure 1). The protocol was approved by the local Research Ethics Committee and written informed consent was obtained in all cases (UFC-CE 422.106).

\section{Sample description}

Patients of both gender aged 18 to 85 years, with time onset of symptoms less than 15 days, neuroimaging excluding non-ischemic lesion, stable clinical-neurological state, and capacity (patients or relatives) to provide a written consent were included. Subjects were excluded if NIHSS was above 25, comprehension deficit was severe enough to prevent evaluation tests, and severe comorbidities were present. Among all, patients who went to bed in their normal state of health and first noticed stroke symptoms upon awakening were classified as WUS.

\section{Clinical evaluation}

Clinical and demographic data included age, gender, and anthropometric measures. Arterial hypertension, diabetes, hyperlipidemia, heart disease, smoking, heavy drinking, sedentary lifestyle, and obesity were all evaluated. Arterial hypertension was defined as a systolic blood pressure $\geq 140 \mathrm{mmHg}$, diastolic blood pressure $\geq 90$ $\mathrm{mmHg}$, and/or current use of antihypertensive medications. ${ }^{15}$ Diabetes was defined as the presence of a fastening $\geq 126 \mathrm{mg} / \mathrm{dL}$, postprandial glucose concentration $\geq$ $200 \mathrm{mg} / \mathrm{dL}$, or diabetes symptoms and a plasmatic glucose concentration (last meal time independent) $\geq 200$ $\mathrm{mg} / \mathrm{dL} .{ }^{16}$ Hyperlipidemia was defined as an alteration in lipid profile, with low density cholesterol $\geq 100 \mathrm{mg} / \mathrm{dL}$, high density cholesterol $<40 \mathrm{mg} / \mathrm{dL}$, and/or triglycerides $>150 \mathrm{mg} / \mathrm{dL} \cdot{ }^{17}$ Previous history of heart disease was informed by patients and/or caregivers. All data were confirmed by chart review. Patients were classified as physically active when involved in moderated to intense physical activity for, at least, 150 minutes/week. Heavy drinking was defined as the ingestion of five or more drinks per day at least once per month or more than 30 drinks per month. Smoking was defined as the use of tobacco for the last 12 months. ${ }^{18}$

The following anthropometric parameters related to cardiovascular risks were evaluated: body mass index (BMI), ${ }^{19}$ neck circumference, ${ }^{20}$ waist circumference, and waist-hip index (WHI) ${ }^{21}$ Neck circumference was considered abnormal if $>43 \mathrm{~cm}$ in men and $>38 \mathrm{~cm}$ in women; waist circumference was abnormal if $>102 \mathrm{~cm}$ in both genders; waist-hip index was considered abnormal if > 0.91 in men and >0.84 in women. Daytime sleepiness was evaluated by the Epworth Sleepiness Scale (ESS):22 the ischemic lesion gravity, through the NIHSS; ${ }^{23}$ the individual's functional capacity, through the MRS; ${ }^{24}$ and the clinical location of the lesion, through the Oxfordshire Community Stroke Project (OCSP). ${ }^{25}$ 


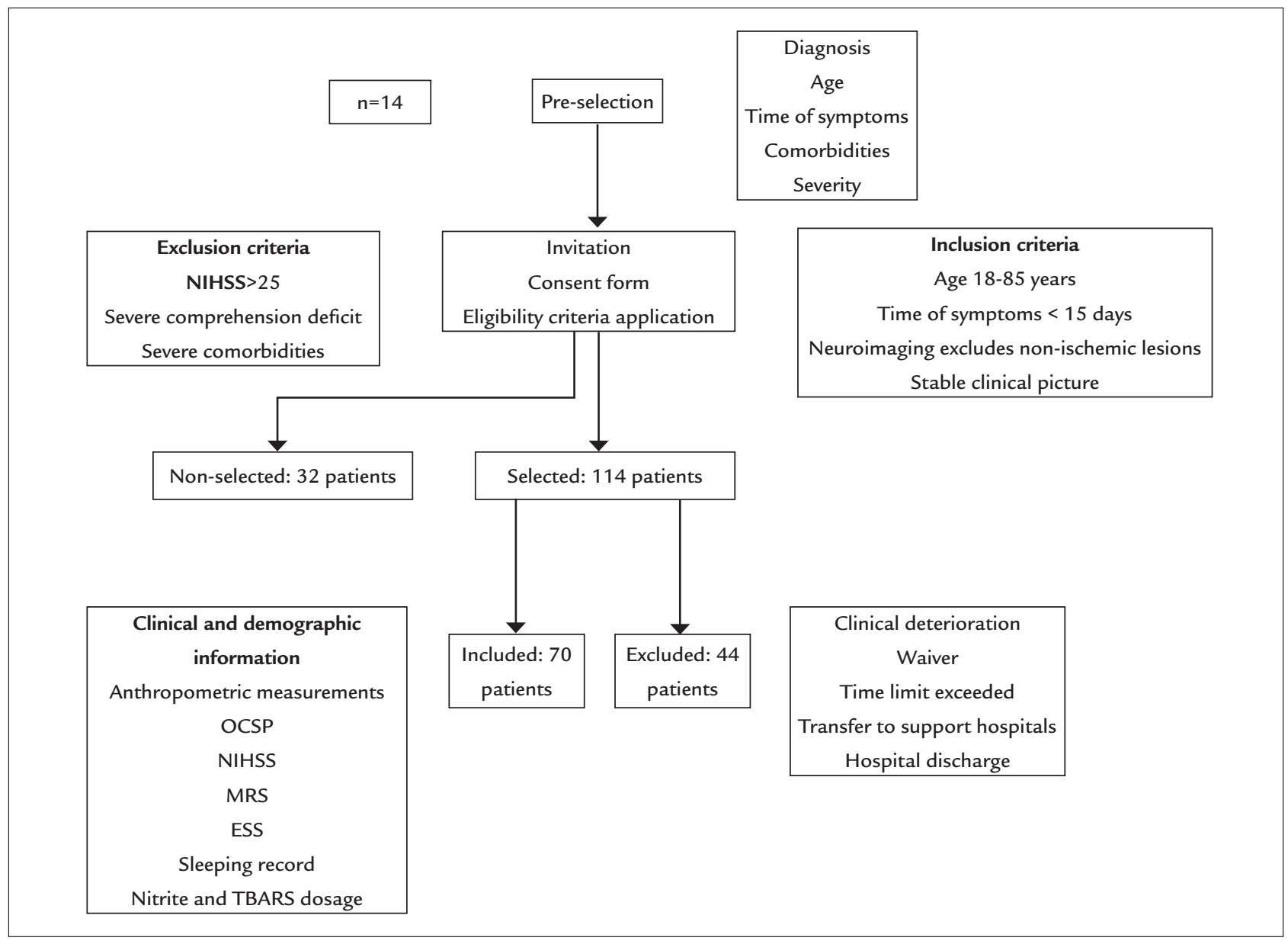

FIGURE 1 Flowchart of patient selection and evaluation.

NIHSS: National Institutes of Health Stroke Scale; OCSP: Oxfordshire Community Stroke Project; MRS: Modified Rankin Scale; ESS: Epworth Sleepiness Scale; TBARS: thiobarbituric acid reactive substances.

\section{Statistical analysis}

Data were examined for normality using the Shapiro-Wilk and for homogeneity of variances the Levene test. The descriptive analysis was presented as absolute numbers, frequency, variation, average, and standard deviation. The Fisher's test or Chi-square test was performed for between group comparisons. The Mann-Whitney's U test for continuous variables and the Student's t test for the variables with normal distribution and homogeneity of variance were performed when adequate. Statistical analysis was performed with the Statistic Package for Social Sciences (SPSS, Norusis, 1993) software for Windows. The level of significance was set at $\mathrm{p}<0.05$. Data are quoted as mean $\pm \mathrm{SD}$.

\section{Results}

Patients ( $\mathrm{N}=70)$ aged from 32 to 83 were studied (mean $=58.5 \pm 13.3)$. Overall, a non-significant male gender $(\mathrm{n}=40$; $57.1 \%)$ predominance over female gender $(\mathrm{n}=30 ; 42.9 \%)$ was observed. Wake-up stroke was diagnosed in 17 patients
(24.3\%); 53 patients (75.7\%) were identified as having had stroke while awake. Arterial hypertension was confirmed within the majority of the cases $(n=47 ; 67.1 \%)$. Diabetes was found in approximately a quarter of the studied population ( $\mathrm{n}=19 ; 27.1 \%)$. Disturb of lipid metabolism was confirmed in 16 patients (22.8\%). Forty-six patients (65.7\%) were identified as physically inactive and 24 (34.3\%) confirmed a history of regular physical activity. Smoking was informed by 22 patients (31.4\%). Heavy drinking was found in 17 patients (26.1\%).

Among all, waist measure was revealed as abnormal $(>102 \mathrm{~cm})$ in 17 patients $(24 \%)$. Women presented more WHI cases (WHI>0.8, 89\%) than men (WHI> 1.0, 55.0\%) (exact Fisher test, $\mathrm{p}=0.002$ ). In the entire group, it was noticed that $40 \%$ of the patients $(n=28)$ had normal BMI and $40 \%$ were overweight ( $n=28)$. Only $20 \%(n=14)$ showed obesity and no differences were found in men ( $37 \%$ normal BMI; $49 \%$ overweight; and $14 \%$ obesity) as compared to women ( $40 \%$ normal BMI; $40 \%$ overweight; and $20 \%$ obe- 
sity) (exact Fisher test, $\mathrm{p}=0.56$ ). Two men presented severe obesity (BMI>35).

Patients with WUS as compared to stroke while awake did not differ in regard to gender and age. Similarly, there was no difference in arterial hypertension, previous smoking habits or heavy drinking between the two groups. In this study, diabetes was more frequent in WUS (exact Fisher test, $\mathrm{p}=0.03$ ). Also, reports of sedentary habits were more common among WUS patients (exact Fisher test, $\mathrm{p}=0.04$ ) (Table 1).

In the overall sample, $62.3 \%$ presented mild, moderated, or few symptoms as evaluated by the NIHSS scale

\section{TABLE 1 Clinical and demographic characteristics and results of behavioral scales of patients with wake-up stroke versus non} wake-up stroke.

\begin{tabular}{|c|c|c|c|c|}
\hline Clinical and demographic characteristics & $\begin{array}{l}\text { All patients } \\
(\mathrm{N}=70)\end{array}$ & $\begin{array}{l}\text { Non wake-up } \\
(n=53)\end{array}$ & $\begin{array}{l}\text { Wake-up } \\
(n=17)\end{array}$ & p-value \\
\hline Male/female, $n$ & $40 / 30$ & $30 / 23$ & $10 / 7$ & ${ }^{\mathrm{a}} 0.87$ \\
\hline$\%$ & $57.1 / 42.9$ & $56.5 / 43.4$ & $58.8 / 41.2$ & \\
\hline Age, range & $32-83$ & $32-82$ & $40-83$ & b0.95 \\
\hline Mean (SD) & $58.5(13.3)$ & $58.6(13.9)$ & $58.4(11.6)$ & \\
\hline Hypertension (yes/no) & $47 / 23$ & $33 / 20$ & $14 / 3$ & ${ }^{\mathrm{a}} 0.15$ \\
\hline$\%$ & $67.1 / 32.9$ & $62.7 / 37.3$ & $82.4 / 17.6$ & \\
\hline Diabetes (yes/no) & $19 / 51$ & $11 / 42$ & $8 / 9$ & ${ }^{\mathrm{a}} 0.03$ \\
\hline$\%$ & $27.1 / 72.9$ & $20.8 / 79.2$ & $47.1 / 52.9$ & \\
\hline Hyperlipidemia (yes/no) & $16 / 49$ & $12 / 41$ & $5 / 12$ & ${ }^{\mathrm{a}} 0.47$ \\
\hline$\%$ & $22.8 / 77.2$ & $22.6 / 77.4$ & $29.4 / 70.6$ & \\
\hline Smoking (yes/no) & $22 / 48$ & $16 / 37$ & $6 / 11$ & ${ }^{\mathrm{a}} 0.69$ \\
\hline$\%$ & $31.4 / 68.6$ & $30.2 / 69.8$ & $35.3 / 64.7$ & \\
\hline Heavy drinking (yes/no) & $17 / 53$ & $10 / 43$ & $5 / 12$ & ${ }^{\mathrm{a}} 0.47$ \\
\hline$\%$ & $26.1 / 73.9$ & $18.86 / 81.14$ & $29.4 / 70.6$ & \\
\hline Heart disease (yes/no) & $6 / 61$ & $6 / 47$ & $1 / 16$ & ${ }^{\mathrm{a}} 0.68$ \\
\hline$\%$ & $8.5 / 91.5$ & $11.3 / 88.7$ & $5.9 / 94.1$ & \\
\hline Sedentary lifestyle (yes/no) & $47 / 23$ & $32 / 21$ & $14 / 2$ & ${ }^{\mathrm{a}} 0.04$ \\
\hline$\%$ & $67.1 / 32.9$ & $60.4 / 39.6$ & $82.4 / 17.6$ & \\
\hline Neck circumference, range & $30.0-54.0$ & $32-52$ & $30-54$ & b0.92 \\
\hline Mean (SD) & $39.8(5.1)$ & $39.7(4.6)$ & $39.9(6.6)$ & \\
\hline BMI, range & $21.4-38.6$ & $21.4-38.6$ & & b 0.74 \\
\hline Mean (SD) & $27.0(3.8)$ & $27.1(3.7)$ & & \\
\hline Waist $(\mathrm{cm})$, range & $65-134$ & $65-134$ & $76-128$ & 0.83 \\
\hline Mean (SD) & $95.5(12.4)$ & $95.3(12.3)$ & $96.12(9.9)$ & \\
\hline Hip (cm), range & $62-124$ & $67-124$ & $62-122$ & 0.90 \\
\hline Mean (SD) & $97.8(11.0)$ & $97.9(9.9)$ & $97.5(14.3)$ & \\
\hline Waist-hip ratio, range & $0.75-1.12$ & $0.80-1.12$ & $0.75-1.04$ & ${ }^{\mathrm{b}} 0.51$ \\
\hline Mean (SD) & $0.96(0.07)$ & $0.97(0.07)$ & $0.95(0.07)$ & \\
\hline \multicolumn{5}{|l|}{ Behavioral questionnaires } \\
\hline NIH Stroke Scale, range & & $0-14$ & $0-18$ & 0.58 \\
\hline Mean (SD) & & $4.8(4.1)$ & $6.2(6.1)$ & \\
\hline Modified Rankin Scale, range & & $0-5$ & $1-5$ & 0.18 \\
\hline Mean (SD) & & 2.0 & 2.5 & \\
\hline OCSP, range & & $1-4$ & $1-4$ & 0.10 \\
\hline Mean (SD) & & 2 & 3 & \\
\hline Epworth Sleepiness Scale, range & & $0-16$ & $0-12$ & 0.46 \\
\hline Mean (SD) & & $6.3(3.7)$ & $7.0(4.1)$ & \\
\hline
\end{tabular}

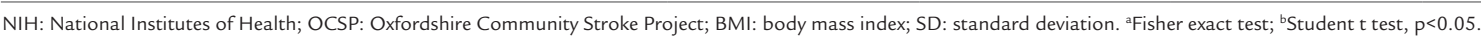


(NIHSS $<5)$. Similarly, as evaluated by the MRS scale, $62.3 \%$ showed indicative signs of a mild stroke $(\mathrm{MR} \leq 2)$. The indication of vascular territories involved as evaluated by the OCSP scale revealed a great variability. The symptoms of daytime sleepiness in the last 30 days (ESS $>10$ ) were identified in $20 \%$ of the patients. Stroke severity (NIHSS), functional performance (MRS), classification of infarct (OCSP), and daytime sleepiness were not different between groups with WUS as compared to stroke while awake (Table 1).

Patients with excessive daytime sleepiness were younger $(\mathrm{p}=0.02)$, had more reports of heavy drinking $(\mathrm{p}=0.03)$, and more records of previous physical inactivity $(\mathrm{p}=0.03)$.
Among patients with excessive daytime sleepiness, a trend for a higher number of cases with WUS and arterial hypertension was observed. Regarding stroke severity as evaluated by the NIHSS and MRS scales, and the vascular territory according to the OCSP scale, no differences were found between patients with and without excessive daytime sleepiness (Table 2).

\section{Discussion}

In this study it is shown that WUS represents approximately a quarter of the ischemic stroke patients. Previous reports indicate a prevalence that varies from 5 to $30 \%$. The thrombolytic therapy for ischemic stroke can only

TABLE 2 Demographic and clinical characteristics of stroke patients with and without daytime sleepiness.

\begin{tabular}{|c|c|c|c|}
\hline & $\begin{array}{l}\text { Without daytime sleepiness } \\
\mathrm{n}=56\end{array}$ & $\begin{array}{l}\text { With daytime sleepiness } \\
n=14\end{array}$ & p-value \\
\hline Gender (M/F) & $31 / 25$ & $10 / 4$ & ${ }^{\mathrm{a}} 0.33$ \\
\hline$\%$ & $55.4 / 44.6$ & $71.42 / 28.58$ & \\
\hline Age, range & $32-83$ & $32-78$ & ${ }^{\mathrm{b}} 0.02$ \\
\hline Mean (SD) & $60.5(12.9)$ & $50.3(13.2)$ & \\
\hline Wake-up stroke (yes/no) & $9 / 45$ & $6 / 8$ & ${ }^{\mathrm{a}} 0.11$ \\
\hline$\%$ & $16.1 / 83.9$ & $42.9 / 57.1$ & \\
\hline Hypertension (yes/no) & $39 / 15$ & $7 / 7$ & ${ }^{\mathrm{a}} 0.17$ \\
\hline$\%$ & $69.6 / 30.4$ & $50 / 50$ & \\
\hline Diabetes (yes/no) & $14 / 40$ & $2 / 10$ & ${ }^{\mathrm{a}} 0.71$ \\
\hline$\%$ & $25 / 75$ & $14.3 / 85.7$ & \\
\hline Hyperlipidemia (yes/no) & $14 / 42$ & $5 / 9$ & ${ }^{\mathrm{a}} 0.71$ \\
\hline$\%$ & $25 / 75$ & $35.7 / 64.3$ & \\
\hline Smoking (yes/no) & $17 / 39$ & $6 / 8$ & ${ }^{\mathrm{a}} 0.49$ \\
\hline$\%$ & $30.4 / 69.6$ & $42.9 / 57.1$ & \\
\hline Heavy drinking (yes/no) & $11 / 45$ & $6 / 8$ & ${ }^{\mathrm{a}} 0.03$ \\
\hline$\%$ & $19.6 / 80.4$ & $42.9 / 57.1$ & \\
\hline Heart disease (yes/no) & $8 / 48$ & $2 / 12$ & ${ }^{\mathrm{a}} 0.36$ \\
\hline$\%$ & $14.3 / 85.7$ & $14.3 / 85.7$ & \\
\hline Sedentary lifestyle (yes/no) & $33 / 23$ & $12 / 2$ & ${ }^{\mathrm{a}} 0.03$ \\
\hline$\%$ & $58.9 / 41.1$ & $85.7 / 14.3$ & \\
\hline Waist $(\mathrm{cm})$, range & $65-134$ & $77-114$ & ${ }^{\mathrm{b}} 0.42$ \\
\hline Mean (SD) & $96.7(12.3)$ & $93.4(12.9)$ & \\
\hline Hip (cm), range & $62-124$ & $85-115$ & ${ }^{\mathrm{b}} 0.54$ \\
\hline Mean (SD) & 98.54 & 96.27 & \\
\hline Neck circumference $(\mathrm{cm})$, range & $30-54$ & $33.5-50$ & ${ }^{\mathrm{b}} 0.25$ \\
\hline Mean (SD) & $39.6(5.4)$ & $41.5(4.1)$ & \\
\hline BMI, range & 21.4-38.6 & $23.0-37.6$ & b0.98 \\
\hline Mean (SD) & $27.1(3.6)$ & $27.1(4.9)$ & \\
\hline Waist-hip ratio, range & $0.75-1.09$ & $0.84-1.12$ & ${ }^{\mathrm{a}} 0.96$ \\
\hline Mean (SD) & $0.97(0.7)$ & $0.97(0.8)$ & \\
\hline
\end{tabular}

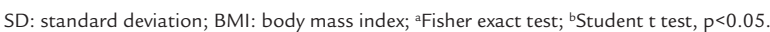


be administrated in a narrow time window. Therefore, considering that patients with WUS may comprise up to $30 \%$ of the ischemic strokes, a significant number of cases may have this alternative of treatment compromised.

It has been reported that the patients with WUS present worse clinical presentation, and, as opposed to it, there are reports showing no difference between WUS and stroke while awake. Our study revealed the latter pattern in the overall sample. In an interesting way, however, the patients with WUS presented more diabetes and a sedentary lifestyle. To the best of our knowledge, similar reports have not been described. A previous study showed a relationship between WUS and smoking. ${ }^{9}$

Daytime sleepiness has been associated with an increase in mortality by any cause and with major occurrence of cerebrovascular diseases. ${ }^{26,27}$ Daytime sleepiness is also a clinical sign of obstructive sleep apnea which by its turn is an independent factor to greater mortality in stroke. ${ }^{28}$ In the current study, $20 \%$ of the patients had excessive daytime sleepiness and this was higher among the younger, in those with history of sedentary lifestyle and heavy drinking. It must be considered that daytime sleepiness is a complex symptom and of probable multifactorial cause. The occurrence of heavy drinking in association with daytime sleepiness suggests an additional cause for neuronal lesions.

Regarding the conundrum of therapy for WUS patients, recently, it has been shown that the characterization of the penumbra zone is a decisive factor for the use of reperfusion therapies. ${ }^{29}$ The perfusion-diffusion mismatch has been the most used method to access the penumbra zone: the diffusion weighted image (DWI) sequence shows the irreversible ischemia area and the perfusion sequence detects the hypoperfusion area. It is important to remember that the hypoperfused lesions without hyperintensity area in the DWI represent the penumbra zone. Therefore, due to its excellent sensibility and specificity in diagnosing stroke in its acute phase, the magnetic resonance imaging can be essential for the patient with stroke. ${ }^{30,31}$ The exam lasts less than 10 minutes, confirms the ischemia, excludes the stroke mimics and identifies the penumbra (perfusion-diffusion mismatch), promoting additional information for the decision taking regarding the thrombolytic therapy. Such procedures would be particularly useful in WUS cases.

Limitations to this study must be acknowledged. Presently, a small sample of patients was involved. However, our results are in agreement with previous reports. Moreover, the frequency of excessive daytime sleepiness, sedentary lifestyle and heavy drinking are noteworthy.

\section{Conclusion}

The current study shows that WUS occurs in approximately $25 \%$ of patients with ischemic stroke. Stroke severity and daytime sleepiness were similar in patients with WUS as compared to stroke while awake. In this study, diabetes and sedentary lifestyle were more frequent in WUS patients. Overall, excessive daytime sleepiness was present in $20 \%$ and was more frequent in patients of younger age, in those with sedentary lifestyle or with heavy drinking.

\section{Resumo}

Wake-up stroke: achados clínicos, sedentarismo e sonolência diurna

Objetivo: wake-up stroke (WUS) define o acidente vascular cerebral (AVC) que ocorre sem horário preciso de início, pois os sintomas manifestam-se ao despertar. Alterações do sono associam-se a maior risco de AVC e doenças cardíacas. Este estudo avalia as características dos pacientes com e sem WUS, a presença de sonolência diurna e os fatores de risco associados.

Método: pacientes com AVC isquêmico foram identificados quanto à presença de WUS. Foram avaliadas as características clínico-demográficas, a gravidade do AVC pela National Institutes of Health Stroke Scale (NIHSS) e pela Modified Rankin Scale (MRS) e o grau de sonolência pela Epworth Sleepiness Scale (ESS).

Resultados: setenta pacientes (57,1\% homens) com idade entre 32 e 80 anos $(58,5 \pm 13,3)$ foram estudados. Wake-up stroke foi observado em $24,3 \%$ dos casos. Hipertensão arterial sistêmica $(67,1 \%)$, diabetes $(27,1 \%)$ e distúrbio do metabolismo lipídico $(22,8 \%)$ foram frequentes. Diabetes e hábitos sedentários foram mais comuns nos casos com WUS ( $\mathrm{p}<0,05)$. Na amostra total, $62,3 \%$ dos casos apresentavam AVC leve, moderado ou com poucos sintomas $(\mathrm{NIHSS}<5)$. Sonolência excessiva diurna (SED) (ESS > 10) foi identificada em $20 \%$ dos pacientes. Não houve diferença entre os grupos com e sem WUS quanto à gravidade do AVC e o grau de sonolência. Pacientes com SED eram mais jovens e mais sedentários $(\mathrm{p}<0,05)$. Os indivíduos com etilismo tinham maior grau de sonolência $(\mathrm{p}=0,03)$.

Conclusão: wake-up stroke manifesta-se em $25 \%$ dos casos de AVC isquêmico. Neste estudo, os pacientes com WUS apresentaram mais diabetes e sedentarismo. Sonolência diurna é frequente e associa-se a hábitos sedentários e etilismo.

Palavras-chave: acidente vascular cerebral isquêmico, sedentarismo, sono, diabetes, alcoolismo. 


\section{REFERENCES}

1. Rimmele DL, Thomalla G. Wake-up stroke: clinical characteristics, imaging findings, and treatment option - an update. Front Neurol. 2014; 5:35.

2. Silva GS, Lima FO, Camargo EC, Smith WS, Singhal AB, Greer DM, et al. Wake-up stroke: clinical and neuroimaging characteristics. Cerebrovasc Dis. 2010; 29(4):336-42.

3. Nadeau JO, Fang J, Kapral MK, Silver FL, Hill MD; Registry of the Canadian Stroke Network. Outcome after stroke upon awakening. Can J Neurol Sci. 2005; 32(2):232-6

4. Jauch EC, Saver JL, Adams HP, Jr., Bruno A, Connors JJ, Demaerschalk BM, et al.; American Heart Association Stroke Council; Council on Cardiovascular Nursing; Council on Peripheral Vascular Disease; Council on Clinical Cardiology. Guidelines for the early management of patients with acute ischemic stroke: a guideline for healthcare professionals from the American Heart Association/American Stroke Association. Stroke. 2013; 44(3):870-947.

5. The National Institute of Neurological Disorders and Stroke rt-PA Stroke Study Group. Tissue plasminogen activator for acute ischemic stroke. N Engl J Med. 1995; 333(24):1581-8.

6. Hacke W, Kaste M, Bluhmki E, Brozman M, Davalos A, Guidetti D, et al. Thrombolysis with alteplase 3 to 4.5 hours after acute ischemic stroke. N Engl J Med. 2008; 359(13):1317-29.

7. Kim BJ, Lee SH, Shin CW, Ryu WS, Kim CK, Yoon BW. Ischemic stroke during sleep: its association with worse early functional outcome. Stroke. 2011; 42(7):1901-6

8. Moradiya Y, Janjua N. Presentation and outcomes of "wake-up strokes" in a large randomized stroke trial: analysis of data from the International Stroke Trial. J Stroke Cerebrovasc Dis. 2013; 22(8):e286-92.

9. Turin TC, Kita Y, Rumana N, Nakamura Y, Takashima N, Ichikawa M, et al. Wake-up stroke: incidence, risk factors and outcome of acute stroke during sleep in a Japanese population. Takashima Stroke Registry 19882003. Eur Neurol. 2013; 69(6):354-9.

10. Mackey J, Kleindorfer D, Sucharew H, Moomaw CJ, Kissela BM, Alwell K, et al. Population-based study of wake-up strokes. Neurology. 2011; 76(19):1662-7.

11. Priou P, Le Vaillant M, Meslier N, Paris A, Pigeanne T, Nguyen XL, et al.; IRSR sleep cohort group. Cumulative association of obstructive sleep apnea severity and short sleep duration with the risk for hypertension. PLoS One. 2014; 9(12):e115666.

12. Cappuccio FP, D'Elia L, Strazzullo P, Miller MA. Sleep duration and allcause mortality: a systematic review and meta-analysis of prospective studies. Sleep. 2010; 33(5):585-92.

13. Yaggi HK, Concato J, Kernan WN, Lichtman JH, Brass LM, Mohsenin V. Obstructive sleep apnea as a risk factor for stroke and death. N Engl J Med. 2005; 353(19):2034-41.

14. Larsson SC, Åkesson A, Wolk A. Primary prevention of stroke by a healthy lifestyle in a high-risk group. Neurology. 2015; 84(22):2224-8.

15. Pickering TG, Hall JE, Appel LJ, Falkner BE, Graves JW, Hill MN, et al.; Council on High Blood Pressure Research Professional and Public Education Subcommittee, American Heart Association. Recommendations for blood pressure measurement in humans: an AHA scientific statement from the
Council on High Blood Pressure Research Professional and Public Education Subcommittee. J Clin Hypertens (Greenwich). 2005; 7(2):102-9.

16. Sacks DB, Arnold M, Bakris GL, Bruns DE, Horvath AR, Kirkman MS, et al. Guidelines and recommendations for laboratory analysis in the diagnosis and management of diabetes mellitus. Diabetes Care. 2011; 34(6):e61-99.

17. Fletcher B, Berra K, Ades P, Braun LT, Burke LE, Durstine JL, et al. Managing abnormal blood lipids: a collaborative approach. Circulation. 2005; 112(20):3184-209.

18. O’Donnell MJ, Xavier D, Liu L, Zhang H, Chin SL, Rao-Melacini P, et al.; INTERSTROKE investigators. Risk factors for ischaemic and intracerebral haemorrhagic stroke in 22 countries (the INTERSTROKE study): a casecontrol study. Lancet. 2010; 376(9735):112-23

19. Bazzano LA, Gu D, Whelton MR, Wu X, Chen CS, Duan X, et al. Body mass index and risk of stroke among Chinese men and women. Ann Neurol. 2010; 67(1):11-20.

20. Preis SR, Massaro JM, Hoffmann U, D’Agostino RB Sr, Levy D, Robins SJ, et al. Neck circumference as a novel measure of cardiometabolic risk: the Framingham Heart study. J Clin Endocrinol Metab. 2010; 95(8):3701-10.

21. Davidson TM, Patel MR. Waist circumference and sleep disordered breathing. Laryngoscope. 2008; 118(2):339-47.

22. Bertolazi AN, Fagondes SC, Hoff LS, Pedro VD, Menna Barreto SS, Johns MW. Portuguese-language version of the Epworth sleepiness scale: validation for use in Brazil. J Bras Pneumol. 2009; 35(9):877-83.

23. Brott T, Marler JR, Olinger CP, Adams HP, Jr., Tomsick T, Barsan WG, et al Measurements of acute cerebral infarction: lesion size by computed tomography. Stroke. 1989; 20(7):871-5.

24. de Haan R, Limburg M, Bossuyt P, van der Meulen J, Aaronson N. The clinical meaning of Rankin 'handicap' grades after stroke. Stroke. 1995; 26(11):2027-30

25. Bamford J, Sandercock P, Dennis M, Burn J, Warlow C. Classification and natural history of clinically identifiable subtypes of cerebral infarction. Lancet. 1991; 337(8756):1521-6.

26. Blachier M, Dauvilliers Y, Jaussent I, Helmer C, Ritchie K, Jouven X, et al Excessive daytime sleepiness and vascular events: the Three City Study. Ann Neurol. 2012; 71(5):661-7.

27. Boden-Albala B, Roberts ET, Bazil C, Moon Y, Elkind MS, Rundek T, et al. Daytime sleepiness and risk of stroke and vascular disease: findings from the Northern Manhattan Study (NOMAS). Circ Cardiovasc Qual Outcomes. 2012; 5(4):500-7.

28. Arzt M, Young T, Peppard PE, Finn L, Ryan CM, Bayley M, et al. Dissociation of obstructive sleep apnea from hypersomnolence and obesity in patients with stroke. Stroke. 2010; 41(3):e129-34

29. Buck D, Shaw LC, Price CI, Ford GA. Reperfusion therapies for wake-up stroke: systematic review. Stroke. 2014; 45(6):1869-75.

30. Odland A, Særvoll P, Advani R, Kurz MW, Kurz KD. Are the current MRI criteria using the DWI-FLAIR mismatch concept for selection of patients with wake-up stroke to thrombolysis excluding too many patients? Scand J Trauma Resusc Emerg Med. 2015; 23(1):22.

31. Thomalla G, Fiebach JB, Ostergaard L, Pedraza S, Thijs V, Nighoghossian N, et al.; WAKE-UP investigators. A multicenter, randomized, double-blind, placebocontrolled trial to test efficacy and safety of magnetic resonance imaging-based thrombolysis in wake-up stroke (WAKE-UP). Int J Stroke. 2014; 9(6):829-36. 